\title{
Click-cross-linked, doxorubicin-loaded hydrogels based on poly(styrene-alt-maleic anhydride)
}

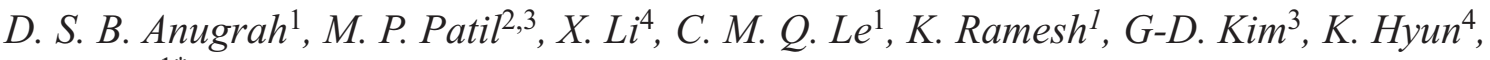 \\ K. T. Lim $^{1 *}$ \\ ${ }^{1}$ Department of Display Engineering, Pukyong National University, 45 Yongso-ro, Nam-gu, 48513 Busan, Republic of \\ Korea \\ ${ }^{2}$ Research Institute for Basic Sciences, Pukyong National University, 45 Yongso-ro, Nam-gu, 48513 Busan, Republic of \\ Korea \\ ${ }^{3}$ Department of Microbiology, College of Natural Sciences, Pukyong National University, 45 Yongso-ro, Nam-gu, \\ 48513 Busan, Republic of Korea \\ ${ }^{4}$ School of Chemical and Biomolecular Engineering, Pusan National University, 46241 Busan, Republic of Korea
}

Received 27 June 2019; accepted in revised form 28 August 2019

\begin{abstract}
A new type of hydrogels based on poly(styrene-alt-maleic anhydride) (PSMA) was prepared via Diels-Alder click chemistry. The formulations consisting of tetrazine-functionalized PSMA as a multi-clickable polymer and norbornene-terminated poly(ethylene glycol) (PEG) as a polymeric cross-linker were used as precursors to give ultrafast hydrogels with controlled structures. The hydrogels formed within several minutes under a physiological condition without any catalyst, and their storage modulus $\left(G^{\prime}\right)$ values were in the range $0.3-1.7 \mathrm{kPa}$ suitable for bio-applications. The pore structure and the release profile of doxorubicin hydrochloride $(\mathrm{DOX} \cdot \mathrm{HCl})$ of the hydrogels could be manipulated by the molecular weight of PEG. The precursors exhibited practically no depressing effect of the normal HEK293 growth, while the DOX $\cdot \mathrm{HCl}$-loaded hydrogel presented significant anticancer activity towards HeLa cells. The results suggested this biocompatible hydrogel as a potential injectable drug depot for tumor sites.
\end{abstract}

Keywords: polymer gels, injectable hydrogel, poly(styrene-alt-maleic anhydride), RAFT polymerization, tetrazine-norbornene click reaction

\section{Introduction}

A hydrogel is a cross-linked three-dimensional product of macromolecular hydrophilic networks. Due to their unique properties, hydrogels have been extensively studied for tissue engineering, especially, they have excellent biocompatibility and the capability to be the type of drug delivery system $[1,2]$. The high water content provides them with properties similar to natural extracellular matrixes. The risk of the drug denaturation and aggregation due to exposure to an organic solvent can be minimized by hydrogels. The internal network makes hydrogels have solid-like properties. Hydrogel networks may be physical gels or chemical gels. Physical gels form through physical interactions, while chemical gels are held together by covalent bonds.

Chemical gel methods for making the internal network have made significant progress so far. Click chemistry, one of the methods, provided hydrogels with moderately high mechanical properties [3-6] and was also useful in biomedical engineering [712]. The emerging studies in click chemistry have generated 'metal-free' reactions. One example of interesting metal-free click chemistry is the inverse 
electron demand Diels-Alder (IEDDA) reaction between tetrazines $(\mathrm{Tz})$ and dienophiles groups (e.g. norbornene, trans-cyclooctene, 1-methyl-cyclopropene, and so on). Many studies have shown that the reaction formed orthogonally cross-linked hydrogels at a very fast rate, and it was air insensitive and proceeded in aqueous media as well as under physiological conditions [13-16].

Over the past decade, injectable hydrogels have attracted much attention owing to simple production processes, excellent properties, and without surgical procedures, which could reduce the patient's discomfort $[17,18]$. Biocompatibility of polymeric hydrogels is an important property, which is used inside the microenvironment of the human body. The materials with marvelous biocompatibility would be necessary for a successful application of injectable hydrogels. Furthermore, fast gelation property is an important requirement in the in-situ injectable hydrogel formation because it prevents the gel precursors from spreading away from the injection site [19, 20]. The advantages of injectable hydrogels make it suitable for cancer localization chemotherapy. Doxorubicin is one of the anticancer drugs widely used in chemotherapy. Traditionally, it is dosed through intravenous injection. This way carries various problems such as dose-dependent cardiotoxicity, and the long-term use of the drug can induce multi-drug resistance. Moreover, it is cytotoxic not only to a cancer cell but also normal tissue [21]. Injectable hydrogels can be a promising approach to overcome these problems by reducing the side effects of chemotherapy. Dadsetan studied oligo(poly(ethylene glycol) fumarate) (OPF) hydrogels with negatively charged sodium methacrylate under UV light $(365 \mathrm{~nm})$ exposure for doxorubicin delivery [22]. The Shen group investigated injectable hydrogels based on the modified PEG for sustaining doxorubicin released [23, 24], but the use of a metal catalyst was required in the modification route of PEG. Other researchers exploited the IEDDA reaction between $\mathrm{Tz}$ and dienophiles for the development of hydrogels [14, 25-27]. For instance, Alge et al. [14] synthesized hydrogels for three-dimensional cell culture using four-arm PEG functionalized with $\mathrm{Tz}$ and peptides cross-linker functionalized with norbornene $(\mathrm{Nb})$. Kawamoto et al. [27] studied Fe-based Metallo-hydrogels for doxorubicin release.

Poly(styrene-alt-maleic anhydride) (PSMA) is one of the versatile synthetic copolymers because of its interesting functionality and bio-compatible properties $[28,29]$. The molecular weight of PSMA can be manipulated precisely by a controlled radical polymerization of readily available monomers and furthermore, its maleic anhydride moieties enable various functionalities in the copolymer backbones by subsequent ring-opening reactions, which open the possibility for its use in large-scale applications. Recently, our group reported on the PSMA based nanogels via Diels-Alder click reaction [30] and grafted PSMA onto multi-walled carbon nanotubes for $\mathrm{pH}-$ responsive release of DOX [31].

Inspired by successful click reactions of PSMA derivatives [29, 30, 32, 33], here, we attempted to produce click-cross-linked hydrogels at fast gelation under physiological conditions. To the best of our knowledge, there has been no published study related to the formation of click-cross-linked PSMA hydrogels. Thus, the primary goal of this work was to exploit the IEDDA click reaction between $\mathrm{Tz}$ and $\mathrm{Nb}$ which were introduced in PSMA and PEG crosslinkers to create a biocompatible and injectable PSMA based hydrogels, as shown in Figure 1a. The PSMA copolymer was prepared with controlled molecular weight by RAFT polymerization. Afterward, the PSMA copolymer was functionalized with 3-( $p$ benzylamino)-1.2.4.5-tetrazine which had an IEDDA reactive $\mathrm{Tz}$ group. $\mathrm{Tz}$ groups incorporated in the PSMA was reacted instantly with dinorbonene chainend functionalized polyethylene glycol (NPN) to produce a hydrogel upon mixing. The properties of the hydrogels were studied in detail. Besides, the release profile of $\mathrm{DOX} \cdot \mathrm{HCl}$ from the hydrogels and the in vitro cell cytotoxicity of the precursors and hydrogels were investigated.

\section{Experimental}

\subsection{Materials}

5-norbornene-2-carboxylic acid (98\%, TCI, Japan), polyethylene glycol (PEG, $M_{\mathrm{n}}=1,4.6$, and $10 \mathrm{kDa}$, Sigma-Aldrich, South Korea), $N, N^{\prime}$-Dicycloexylcarbodiimide (DCC, 99\%, Sigma-Aldrich, South Korea), 4-(dimethylamino) pyridine (DMAP, 99\%, SigmaAldrich, South Korea) were used as received. $\mathrm{DOX} \cdot \mathrm{HCl}$ was supplied from Boryung Pharm. Co. (Seoul, South Korea). Other chemicals and solvents of analytical grade were used as received. Minimum Essential Medium (MEM) was obtained from Cellgro (Manassas, VA, USA). The EZ-Cytox cell viability assay solution WST- $1{ }^{\circledR}$ (2-(4-iodophenyl)-3- 


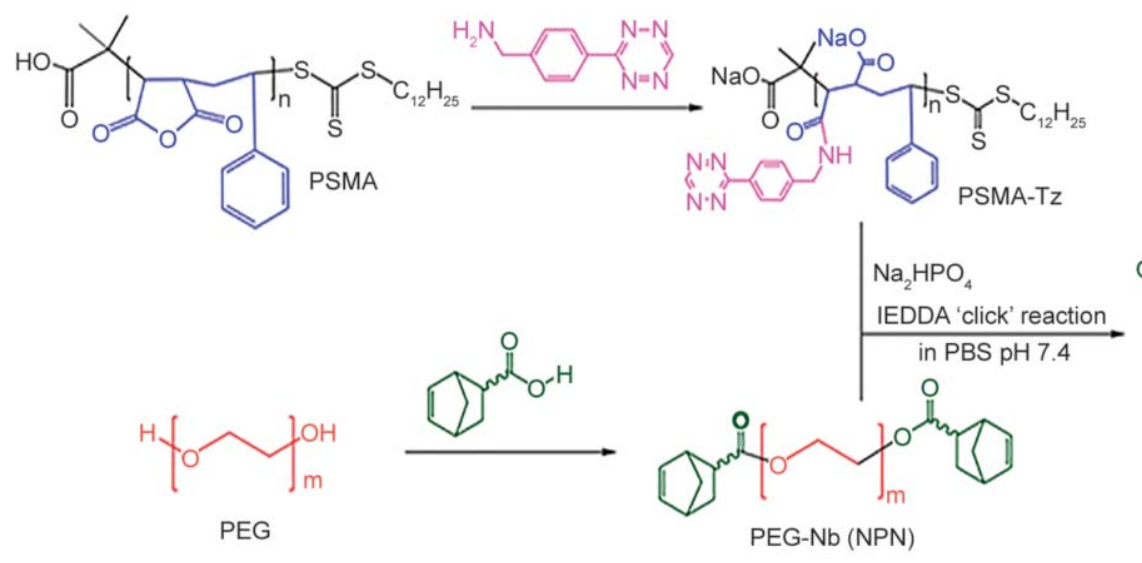

a)

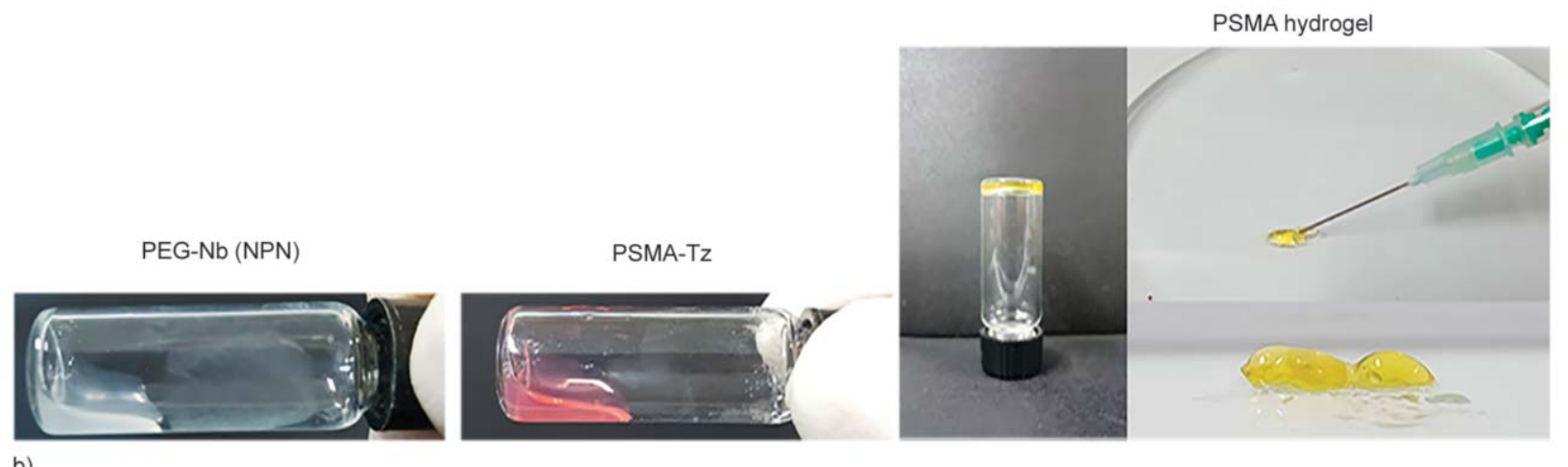

b)

Figure 1. (a) Scheme for PSMA hydrogels and (b) pictures of NPN, PSMA 5 k-Tz, and PSMA hydrogels.

(4-nitrophenyl)-5-(2,4-disulfophenyl)-2H-tetrazolium, monosodium salt) was obtained from Daeil Lab Services (South Korea). Fetal bovine serum (FBS) were purchased from Sigma-Aldrich, USA. 96-well plates were supplied by SPL Lifesciences (Gyeonggi, South Korea). Some materials were synthesized as reported in previous literatures, such as 2-(dodecylthiocarbonothioylthio)-2-methyl propanoic acid (DDMAT) [34], 3-(p-benzylamino)-1,2,4,5-tetrazine $[35,36]$, and PSMA $M_{\mathrm{n} \mathrm{NMR}}=5 \mathrm{kDa}\left(\mathrm{PSMA}_{5 \mathrm{k}}\right)($ Figure 2) [32].

\subsection{Measurement}

The products were characterized by Fourier transform infrared (FTIR, Agilent Cary640 spectrometer, Agilent Technologies, USA, in the range 4000$650 \mathrm{~cm}^{-1}$ with $\mathrm{KBr}$ pellets), ${ }^{1} \mathrm{H}$ and ${ }^{13} \mathrm{C}$ NMR (with a $600 \mathrm{MHz}$ NMR spectrometer, Jeol, USA), and UVVis (with a spectrophotometer Optizen POP, Mecasys Co., Ltd, South Korea). Gel permeation chromatography (GPC, Agilent 1200 Series, Agilent Technologies, USA, equipped with a RID detector, HP 1100 pump, and PL gel columns, $N, N$-dimethylacetamide with $50 \mathrm{mmol}$ lithium chloride was used as a solvent at $50{ }^{\circ} \mathrm{C}$ with a flow rate of $1 \mathrm{ml} / \mathrm{min}$ ) was used to measure molecular weight distribution $\left(\nexists, M_{\mathrm{w}} / M_{\mathrm{n}}\right)$. Morphological structures were observed by scanning electron microscopy (SEM, VEGA-II, TESCAN, USA, accelerating voltage of $15 \mathrm{kV}$ ). The rheological study of hydrogels was carried out by using a strain-controlled rheometer (ARES-G2, TA Instruments, USA, with an $8 \mathrm{~mm}$ diameter parallel plate fixture). The storage modulus $\left(G^{\prime}\right)$ of the hydrogels was monitored over frequency in the range 0.1$100 \mathrm{rad} / \mathrm{s}$ and with constant strain amplitude of 0.1 within the linear viscoelastic regime at $37^{\circ} \mathrm{C}$.

\subsection{Synthesis of poly(styrene-alt-maleic anhydride) tetrazine (PSMA (5k -Tz)}

The copolymer PSMA $5 \mathrm{k}(1.87 \mathrm{mmol}$ of maleic anhydride groups, $385 \mathrm{mg}$ ) and 3-( $p$-benzylamino)1,2,4,5-tetrazine (pink solid) (1.87 mmol, $350 \mathrm{mg}$ ) were dissolved in anhydrous dimethylformamide (DMF) $(1.5 \mathrm{ml})$. After reaction at $60^{\circ} \mathrm{C}$ for $4 \mathrm{~h}$ under nitrogen atmosphere, the reaction solution was precipitated into an excess amount of $10 \%$ acetic acid. 


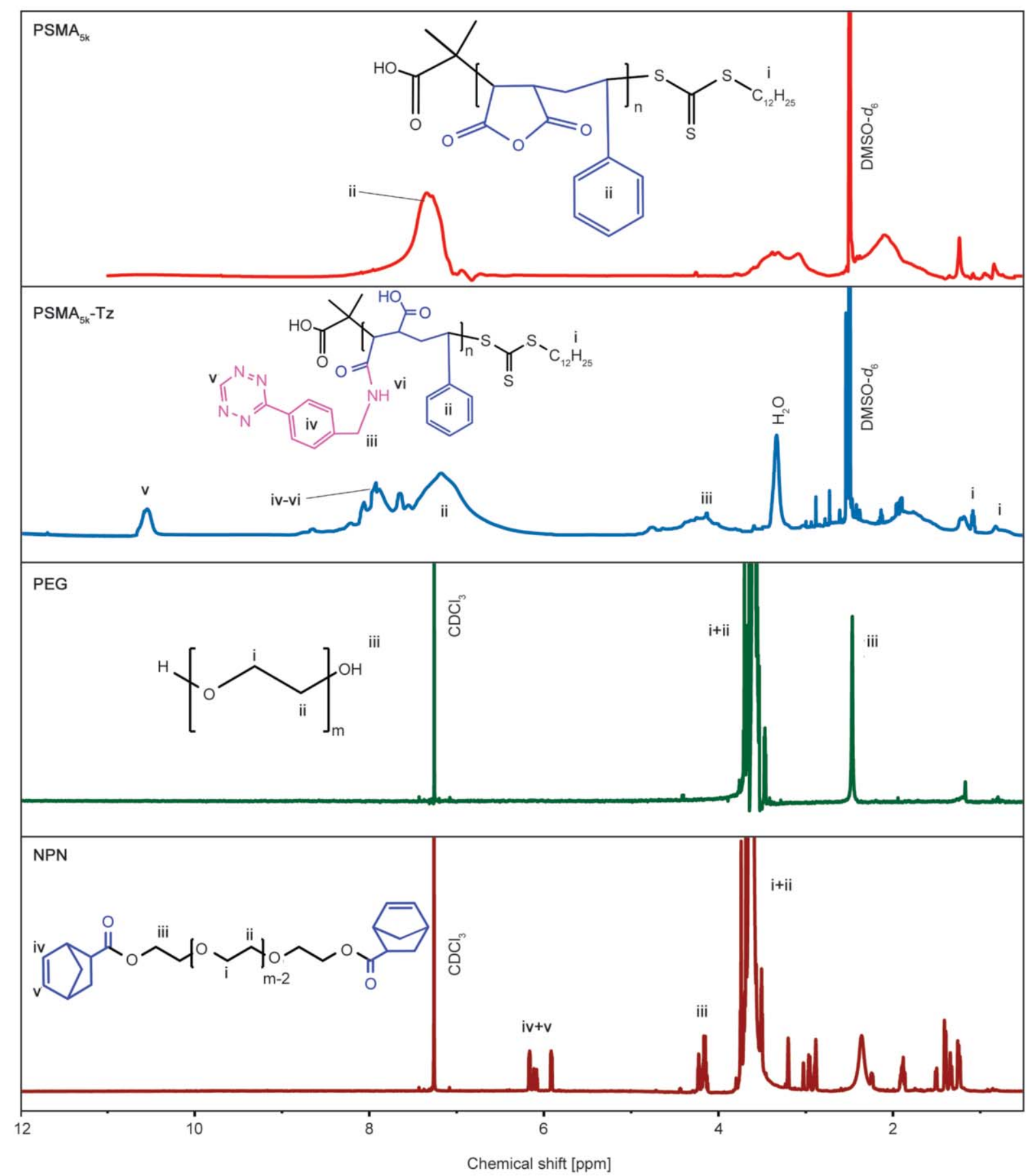

Figure 2. ${ }^{1} \mathrm{H}$ NMR spectra of PSMA ${ }_{5 \mathrm{k}}$, PSMA ${ }_{5 \mathrm{k}}-\mathrm{Tz}, \mathrm{PEG}$, and NPN.

The collected polymer was washed with tetrahydrofuran (THF) to remove unfunctionalized PSMA $\mathrm{A}_{5 \mathrm{k}}$. The product, $\mathrm{PSMA}_{5 \mathrm{k}}-\mathrm{Tz}$ was dissolved in methanol and precipitated into diethyl ether. $\mathrm{PSMA}_{5 \mathrm{k}}-\mathrm{Tz}$ was dissolved in $10 \mathrm{ml}$ of $0.2 \mathrm{M} \mathrm{Na}_{2} \mathrm{HPO}_{4}$ under sonication and purified by dialysis (MWCO $3.5 \mathrm{kDa}$ ) to remove an excess amount of salts. The pure PSMA $_{5 \mathrm{k}^{-}}$ Tz was collected after removing water with a rotary evaporator at $80^{\circ} \mathrm{C}$ and 20 torrs. Afterward, the $\mathrm{PSMA}_{5 \mathrm{k}}-\mathrm{Tz}$ was dried overnight in vacuo at $40^{\circ} \mathrm{C}$ to produce pink solid (0.725 g, yield: $98.6 \%) .{ }^{1} \mathrm{H}$ NMR
(600 MHz, DMSO) (Figure 2); $\delta 10.42-10.70$ (br, 23H), 7.0-8.5 (br, 230H), 3.9-4.89 (br, 46H), 1.20$1.47(\mathrm{~m}, 18 \mathrm{H}), 0.85(\mathrm{t}, 3 \mathrm{H})$.

\subsection{Synthesis of the two-arm}

\section{PEG-norbornene (NPN) cross-linker}

In a dry $250 \mathrm{ml}$ round bottom flask with a Tefloncoated magnetic spin bar, PEG $\left(M_{\mathrm{n}}=1,4.6\right.$, or $10 \mathrm{kDa}$ ) was dissolved in dry DCM with $0.3 \mathrm{eq}$. (molar equivalent with respect to hydroxyls) of DMAP, and 3.3 eq. of triethylamine under a nitrogen 
atmosphere. In a $50 \mathrm{ml}$ vial, DCC was dissolved in dry DCM and reacted with 3 eq. of 5-norbornene-2carboxylic acid for $30 \mathrm{~min}$. Afterward, the norbornene solution was transferred dropwise into the flask. The combined solution was stirred for $30 \mathrm{~min}$ in an ice bath and continuously stirred overnight at room temperature. Next, the mixture was filtered, and the solvent was evaporated to give a viscous liquid. The liquid was precipitated twice in cold diethyl ether and dried in a vacuum oven to produce $\mathrm{NP}_{1 \mathrm{k}} \mathrm{N}$, $\mathrm{NP}_{4.6 \mathrm{k}} \mathrm{N}, \mathrm{NP}_{10 \mathrm{k}} \mathrm{N} .{ }^{1} \mathrm{H}$ NPN NMR $\left(600 \mathrm{MHz}, \mathrm{CDCl}_{3}\right)$ (Figure 2); $\delta 5.79-6.28(\mathrm{~m}, 2 \mathrm{H}), 4.09-4.24(\mathrm{~m}, 2 \mathrm{H})$, 3.43-378 (m, 416H).

\subsection{Preparation of PSMA hydrogels}

The dry PSMA Pk $-\mathrm{Tz}$ was dissolved in PBS (pH 7.4, $0.01 \mathrm{M})$ to make $20 \%(\mathrm{w} / \mathrm{v})$ solutions. The two precursor solutions of PSMA $\mathrm{Pk}_{5 \mathrm{k}}$-Tz and NPN were mixed gently at equimolar Tz: $\mathrm{Nb}(1: 1)$ in a $1.5 \mathrm{ml}$ tube to form PSMA hydrogels. The tube was inverted at time intervals to observe if the gel flowed. The gelation time was measured by a time meter. The hydrogel compositions and abbreviated names were tabulated in Table 2.

\subsection{Morphological observation of the PSMA hydrogel}

The cross-sectional morphology of PSMA hydrogels was examined by SEM. The hydrogels were swollen completely in DI water at room temperature for 2 days and then freeze-dried in vacuo for 2 days. The freeze-dried hydrogels were put in liquid $\mathrm{N}_{2}$ and then cut using a sharp blade. Finally, the hydrogels were coated with a conductive layer of gold. The morphological images of PSMA hydrogels were taken randomly.

\subsection{Hydrogel swelling ratio measurements}

Equilibrium swelling properties of hydrogels were examined by the gravimetric method. After the hydrogel was fabricated, it was freeze-dried in $-40{ }^{\circ} \mathrm{C}$ for $24 \mathrm{~h}$ to assess dry weight $\left(W_{\mathrm{D}}\right)$. Next, the hydrogel was swelled to equilibrium in PBS (pH 7.4, 0.01 M) for $24 \mathrm{~h}$ at $37^{\circ} \mathrm{C}$. The sample was removed from PBS, and the excess PBS on the surface was wiped quickly by a filter paper before weighing $\left(W_{\mathrm{s}}\right)$. The swelling ratio (SR) was calculated according to Equation (1). The experiment was performed in triplicate:
$S R=\frac{W_{\mathrm{s}}-W_{\mathrm{D}}}{W_{\mathrm{D}}} \cdot 100 \%$

\subsection{Preparation of DOX $\cdot \mathrm{HCl}-\mathrm{loaded}$ PSMA hydrogels and in vitro $\mathrm{DOX} \cdot \mathrm{HCl}$ release}

DOX $\cdot \mathrm{HCl}$ was prepared at the concentration of $0.5 \mathrm{mg} / \mathrm{ml}$ in PBS ( $\mathrm{pH} 7.4,0.01 \mathrm{M}$ ) and separately added to PSMA $\mathrm{Ak}_{5 \mathrm{k}}-\mathrm{Tz}$ and NPN solutions prepared in the previous section. The DOX.HCl-loaded PSMA hydrogels $(0.5 \mathrm{mg} / \mathrm{ml})$ were individually formed in $5 \mathrm{ml}$ vials. PBS (pH 6.5 or $7.4,3 \mathrm{ml}$ ) was added to the vials, and they were incubated in a horizontal shaker at $100 \mathrm{rpm}$ and $37^{\circ} \mathrm{C}$. After specified time intervals, the filtrate $(0.5 \mathrm{ml})$ was collected from each of the vials and replaced with a fresh PBS solution $(0.5 \mathrm{ml})$ at $37^{\circ} \mathrm{C}$. The mass of loaded DOX $\cdot \mathrm{HCl}$ was calculated from the absorbance at $485 \mathrm{~nm}$ in UV-Vis spectra with a standard calibration curve of $\mathrm{DOX} \cdot \mathrm{HCl}$ in the same PBS solution. The cumulative drug release (CDR) was calculated by the Equation (2):

$\mathrm{CDR}=\frac{x_{\mathrm{n}}+\sum_{\mathrm{i}=0}^{\mathrm{n}-1} x_{\mathrm{i}}}{x_{\mathrm{o}}}$

Where $x_{\mathrm{n}}$ is the mass of $\mathrm{DOX} \cdot \mathrm{HCl}$ of the aliquot at time $t$ and $n$ is the total number of aliquots extracted until time $t$. Symbol $x_{\mathrm{o}}$ is the original mass of DOX $\cdot \mathrm{HCl}$ loaded, $x_{\mathrm{i}}$ is the mass of DOX of the aliquot. All experiments were performed in triplicate, and the average data were presented. The amount of DOX $\cdot \mathrm{HCl}$ released was calculated using standard calibration curves prepared with known concentrations of $\mathrm{DOX} \cdot \mathrm{HCl}$.

\subsection{Cell lines and cell culture}

Non-cancerous HEK293 (human embryonic kidney) and $\mathrm{HeLa}$ (human cervix adenocarcinoma) cancer cells were purchased from American Type Culture Collection (USA). The cells were cultured and maintained in a MEM medium. The media were supplemented with heat-inactivated $10 \%$ FBS and $1 \%$ antibiotics $(100 \mu \mathrm{g} / \mathrm{ml}$ Penicillin and $100 \mu \mathrm{g} / \mathrm{ml}$ streptomycin). The cell cultures were incubated at $37^{\circ} \mathrm{C}$ with a $5 \% \mathrm{CO}_{2}$ humidified atmosphere and the culture medium was replaced on the interval of every two days. 


\subsection{In vitro cell cytotoxicity assay}

The cytotoxic tests of precursors, blank hydrogels, and $\mathrm{DOX} \cdot \mathrm{HCl}$-loaded hydrogels were conducted by using the MTT method. This assay was performed as described in the previous literature [24] with some modification. The sample of precursors was prepared in a PBS solution of $\mathrm{pH}$ 7.4. On the other hand, blank hydrogels (PSMA hydrogel 1, 4.6 and 10) and DOX $\cdot \mathrm{HCl}$-loaded hydrogels (PSMA hydrogel 1, 4.6 and $10 \mathrm{kDa}$ ) were introduced in PBS solutions of pH 7.4 and saturated at $37^{\circ} \mathrm{C}$ for 2 days. Extracts were kept for cell viability assessment after the hydrogels were removed from the solution. All solutions were purified by filtration (Minisart ${ }^{\circledR}$ syringe filter, $0.2 \mu \mathrm{m}$, Germany).

In the first step, exponential phases of HEK293 and HeLa cells (100 $\mu 1 ; 1$ X 104 cells/well) were seeded on 96 well plates in triplicates. The cell was incubated for $24 \mathrm{~h}$ at $37^{\circ} \mathrm{C}$ in a $5 \% \mathrm{CO}_{2}$ humidified atmosphere. In the second step, the cell medium was replaced by fresh media $(100 \mu \mathrm{l})$ containing precursors with different concentrations $(0.25,0.50,0.75,1.0$, $0.25,1.50,1.75$, and $2.0 \mathrm{mg} / \mathrm{ml}$ ) on HEK293 cells and blank hydrogels, DOX $\cdot \mathrm{HCl}$-loaded hydrogel extracts $(15 \mu \mathrm{g} / \mathrm{ml}$ equivalent $\mathrm{DOX} \cdot \mathrm{HCl})$ and $\mathrm{DOX} \cdot \mathrm{HCl}$ $(15 \mu \mathrm{g} / \mathrm{ml})$ on HeLa cells were incubated for $24 \mathrm{~h}$ at the same conditions mentioned above. In the third step, the cell media were replaced with $100 \mu 1$ media together with $10 \mu \mathrm{l}$ of WST- $1^{\circledR}$ cell viability solution. The 96 well plates were further incubated for $3 \mathrm{~h}$ at the same conditions mentioned above. Finally, the absorbance of the reaction was measured using an ELISA microplate reader (Molecular Devices, USA) at $460 \mathrm{~nm}$ and cell inhibitory rates were considered by relative cell viability.

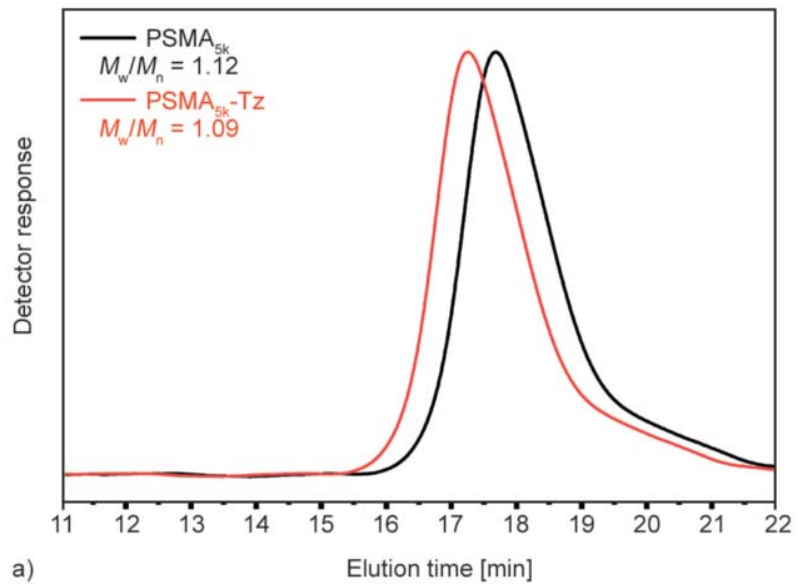

\section{Results and discussion}

\subsection{Synthesis and characterization of precursors}

The PSMA hydrogels were produced as the scheme in Figure 1a. The copolymer, PSMA $5 \mathrm{k}$ was prepared by RAFT polymerization with controlled molecular weight, and then $\mathrm{Tz}$ pendant groups were grafted onto $\mathrm{PSMA}_{5 \mathrm{k}}$ by the reaction between anhydride groups of PSMA and Tz-amine. The preparation of the two-arm NPN cross-linkers was performed by using the Steglich esterification method between PEG and 5-norbornene-2-carboxylic acid in the presence of DCC and DMAP in DCM. NPN was prepared with PEGs of different molecular weights $\left(M_{\mathrm{n}}=1\right.$, 4.6 , and $10 \mathrm{kDa}$ ) to investigate the correlation between the molecular weight and the mesh size and release profile of resulting hydrogels. Both NPN and $\mathrm{PSMA}_{5 \mathrm{k}}$-Tz were translucent, as shown in Figure $1 \mathrm{~b}$, and PSMA $5 \mathrm{k}^{-} \mathrm{Tz}$ was slightly reddish due to the natural color of Tz.

Table 1 indicates that the precursors were synthesized with high yield $(>80 \%)$ and had narrow molecular weight distributions $(\bigoplus<1.3)$ Figure 3. The ${ }^{1} \mathrm{H}$ NMR spectra were used to confirm the molecular structure of precursors (Figure 2). The typical proton peaks of PSMA ${ }_{5 \mathrm{k}}$ were observed at 7.0-7.9 ppm and at 1.2 and $0.85 \mathrm{ppm}$, which are assigned to benzyl (ii) and alkyl protons of the RAFT moiety (i), respectively. The repeating unit was calculated by equating the peak area of benzyl and $n$-alkyl peaks in the spectrum. The ${ }^{1} \mathrm{H}$ NMR spectrum of PSMA $\mathrm{Ak}_{5 \mathrm{k}}$-Tz showed the presence of Tz-amine (iii, iv+vi, $\mathbf{v}$ ) at peaks of $3.92-4.89,7.5-8.32$, and $10.42-10.70$ ppm, indicating the successful functionalization of PSMA 5 . The methylene protons and hydroxyl protons in the chain

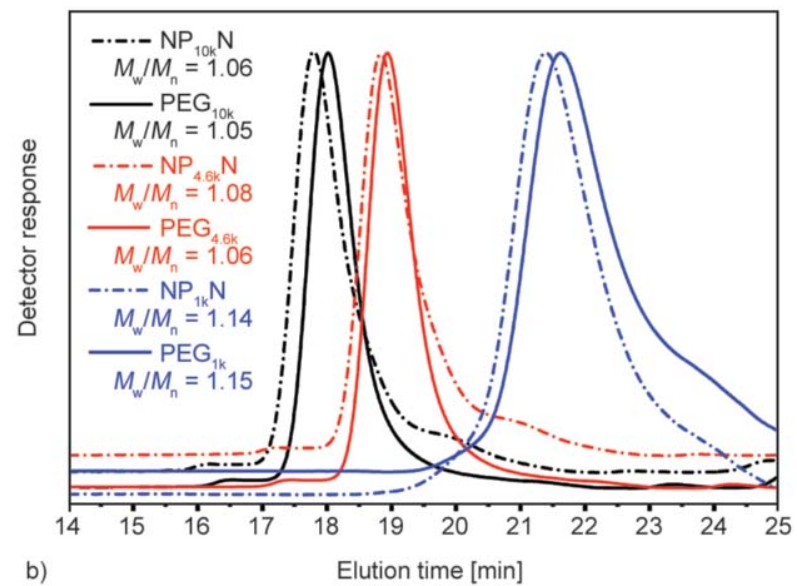

b)

Figure 3. GPC chromatogram; (a) comparison between PSMA 5 k and PSMA $\mathrm{Pk}_{5 \mathrm{k}}$-Tz (b) comparison of PEG and NPN. 
Table 1. Characteristics of precursors.

\begin{tabular}{|c|c|c|c|c|c|c|}
\hline \multirow{2}{*}{ Polymers } & \multicolumn{2}{|c|}{ Feed ratio } & \multirow{2}{*}{$\begin{array}{c}\text { Conv. } \\
{[\%]}\end{array}$} & \multirow{2}{*}{$\begin{array}{c}M_{\mathrm{n} \text { theo. }} \\
{\left[\mathrm{g} \cdot \mathrm{mol}^{-1}\right]}\end{array}$} & \multirow{2}{*}{$\begin{array}{c}M_{\mathrm{n}, \mathrm{NMR}} \\
{\left[\mathrm{g} \cdot \mathrm{mol}^{-1}\right]}\end{array}$} & \multirow{2}{*}{$\boldsymbol{D}\left(M_{\mathrm{w}} / M_{\mathrm{n}}\right)^{\mathrm{b}}$} \\
\hline & {$[\mathbf{M}]_{\text {Tz }} /[\mathbf{M}]_{\text {PSMA }}$} & {$[\mathbf{M}]_{\mathbf{N b}} /\left[\mathbf{M}_{] \mathbf{P E G}}\right.$} & & & & \\
\hline $\mathrm{PSMA}_{5 \mathrm{k}}-\mathrm{Tz}$ & 25 & - & 92.0 & 10100 & 9321 & 1.09 \\
\hline $\mathrm{NP}_{1 \mathrm{k}} \mathrm{N}$ & - & 2 & 98.5 & 1211 & 1200 & 1.14 \\
\hline $\mathrm{NP}_{4.6 \mathrm{k}} \mathrm{N}$ & - & 2 & 97.6 & 4823 & 4818 & 1.06 \\
\hline $\mathrm{NP}_{10 \mathrm{k}} \mathrm{N}$ & - & 2 & 96.0 & 10197 & 10186 & 1.08 \\
\hline
\end{tabular}

${ }^{\mathrm{a} C}$ Conversion was determined by gravimetric analysis

${ }^{\mathrm{b}}$ molecular weight distribution was determined by GPC

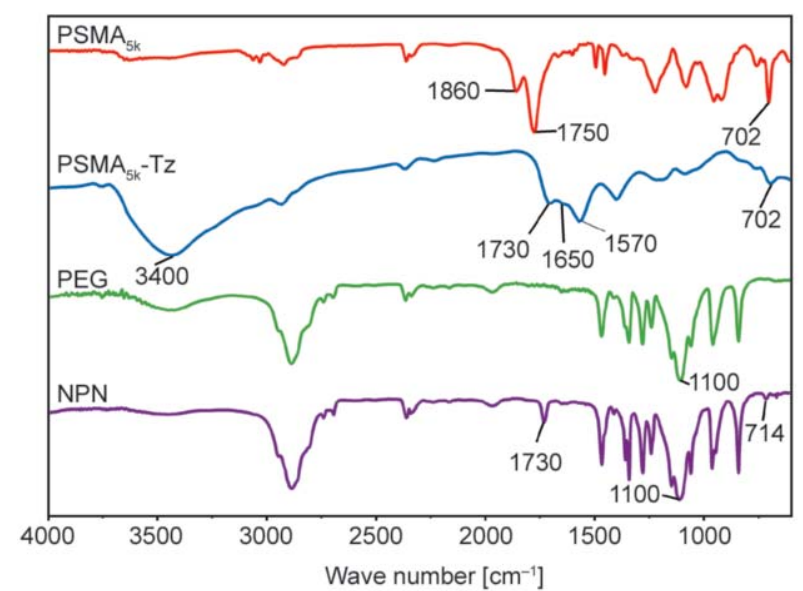

Figure 4. FTIR spectra of PSMA 5 , PSMA $_{5 \mathrm{k}}-\mathrm{Tz}, \mathrm{PEG}$, and NPN.

of PEG were shown at 3.61 (i+ii) and 2,46 ppm (iii). After PEG was functionalized with norbornene, the signal of hydroxyl protons disappeared, while the typical signal of norbornene appeared at 6,14, 5,90, $3.17,2.88,1.8$, and $1.3 \mathrm{ppm}(\mathbf{i v}+\mathbf{v})$.

The FTIR analysis was used to detect molecular changes in precursors (Figure 4). The FTIR spectrum of PSMA $5 \mathrm{k}$ showed cyclic anhydride bands at 1750 and $1860 \mathrm{~cm}^{-1}$ and benzyl group at $702 \mathrm{~cm}^{-1}$. After the amidation reaction, the signals of the cyclic anhydride ring disappeared, and new bands of the

Table 2. Summary of the abbreviations of the hydrogels.

\begin{tabular}{|l|c|c|}
\hline \multirow{2}{*}{ Hydrogel } & \multicolumn{2}{|c|}{$\begin{array}{c}\boldsymbol{M}_{\mathbf{n}, \mathbf{N M R}} \\
{\left[\mathbf{g} \cdot \mathbf{m o l}^{-\mathbf{1}} \mathbf{]}\right.}\end{array}$} \\
\cline { 2 - 3 } & PSMA $_{\mathbf{5 k}} \mathbf{- T z}$ & NPN \\
\hline PSMA hydrogel 1 & 9321 & 1200 \\
\hline PSMA hydrogel 4.6 & 9321 & 4818 \\
\hline PSMA hydrogel 10 & 9321 & 10197 \\
\hline
\end{tabular}

Table 3. Characteristics of PSMA hydrogels.

\begin{tabular}{|l|c|c|c|}
\hline & $\begin{array}{c}\text { PSMA } \\
\text { hydrogel 1 }\end{array}$ & $\begin{array}{c}\text { PSMA } \\
\text { hydrogel 4.6 }\end{array}$ & $\begin{array}{c}\text { PSMA } \\
\text { hydrogel 10 }\end{array}$ \\
\hline Gelation time [s] & $439.8 \pm 19$ & $776.3 \pm 13$ & $1084 \pm 7$ \\
\hline Swelling ratio [\%] & $4.92 \pm 0.40$ & $8.61 \pm 0.97$ & $14.58 \pm 2.02$ \\
\hline Storage modulus [kPa] & $1.76 \pm 0.13$ & $0.68 \pm 0.092$ & $0.38 \pm 0.05$ \\
\hline
\end{tabular}

amide (at 1730 and, $1650 \mathrm{~cm}^{-1}$ ) and the signal of secondary $\mathrm{N}-\mathrm{H}$ (at 3400 and $1570 \mathrm{~cm} \mathrm{~cm}^{-1}$ ) were formed. The characteristic bands of PEG appear at 2886 and $1100 \mathrm{~cm}^{-1}$. After esterification with norbornene, the new bands indicated esters at $1730 \mathrm{~cm}^{-1}$, and cis disubstituted alkenes from norbornene emerge at $714 \mathrm{~cm}^{-1}$. Thus the ${ }^{1} \mathrm{H}$ NMR and FTIR data confirmed the successful synthesis of the precursors.

\subsection{Preparation and characterization of hydrogels}

Three kinds of hydrogels with varying the molecular weight of cross-linkers were prepared via IEDDA reaction by mixing PSMA $5 \mathrm{k}^{-T z}$ and NPN in aqueous phase under a physiological condition. The mixture of NPN and PSMA ${ }_{5 \mathrm{k}}-\mathrm{Tz}$ was put into a syringe and easily injected through a 26 -gauge needle to produce promptly the PSMA hydrogel where the color changed to yellowish as seen in Figure 1b. Hydrogels formed from the cross-linkers of different molecular weights were expected to possess different properties such as gelation time, swelling ratio, mechanical properties, porous network structure, and drug release profile. The gelation process of PSMA hydrogels was investigated by the tube-inversion method. As summarized in Table 3, the PSMA hydrogel 1, 4.6, and 10 became gels within $439.8 \pm 19$, $776.3 \pm 13$, and $1084 \pm 7 \mathrm{~s}$, respectively. The result revealed that PSMA hydrogels had ultrafast gelation property and the gelation time lengthened with increasing the molecular weight of the cross-linker, NPN. The IEDDA cross-linking method in the PSMA hydrogel was monitored using an FTIR spectrometer and a UV-Vis spectrometer [16, 37]. The PSMA hydrogel 4.6 formulations were used as a reference. As depicted in Figure 5, the band of cis disubstituted alkenes from norbornene at $714 \mathrm{~cm}^{-1}$ disappeared in the spectrum of PSMA hydrogel 4.6. The spectrum also showed the broad peak at around $1620 \mathrm{~cm}^{-1}$ corresponding to $-\mathrm{C}=\mathrm{N}-$ and $\mathrm{N}-\mathrm{H}$ bonds from the IEDDA adducts. As shown in Figure 6, the 


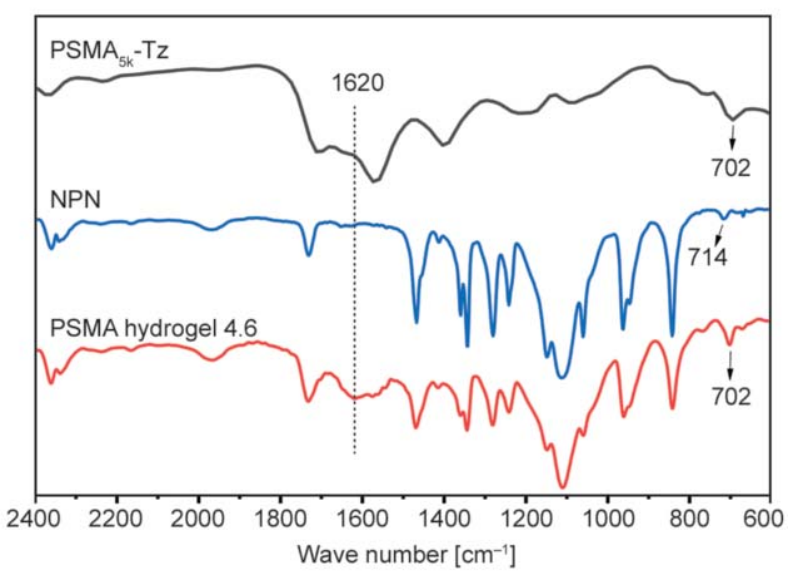

Figure 5. Comparison FTIR spectra of $\mathrm{PSMA}_{5 \mathrm{k}}-\mathrm{Tz}, \mathrm{NPN}$, and PSMA hydrogel 4.6.

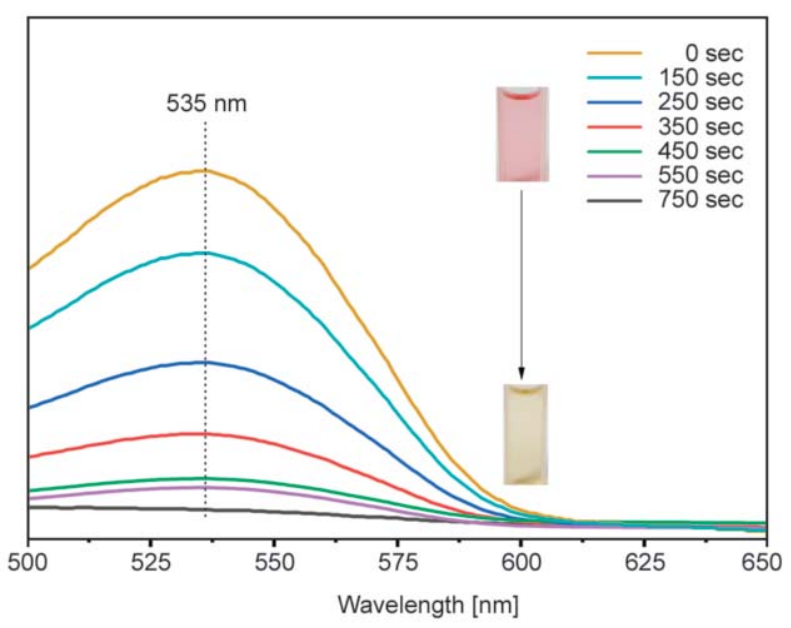

Figure 6. UV-Vis trace spectra showing the progress of IEDDA reaction in PSMA hydrogel 4.6.

PSMA $_{5 \mathrm{k}}-\mathrm{Tz}$ represented the maximum absorbance at $535 \mathrm{~nm}$ due to tetrazine groups. The signal absorbance decreased gradually in each probe time upon the formation of the IEDDA adducts between tetrazine and norbornene groups. Those results verified that the IEDDA reaction between PSMA ${ }_{5 \mathrm{k}}-\mathrm{Tz}$ and NPN occurred completely.

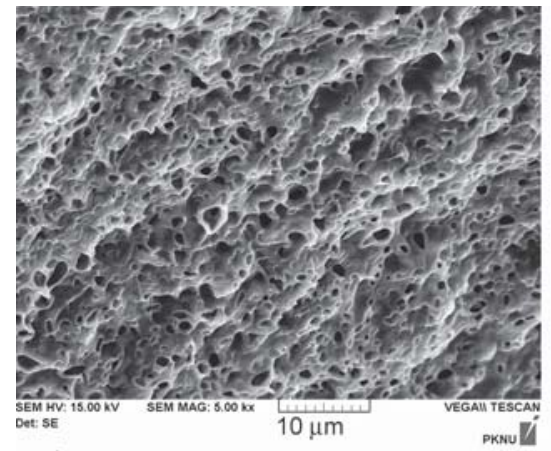

a)

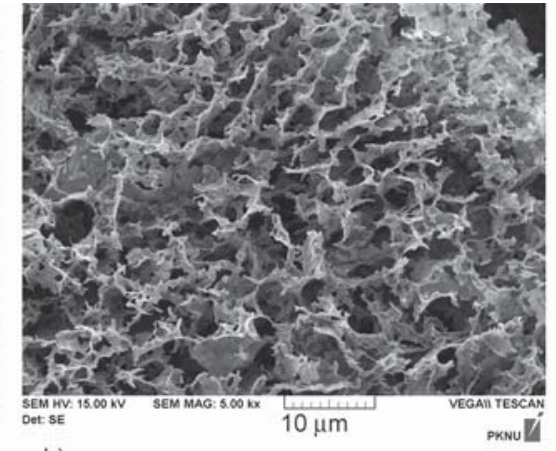

b)
The cross-section SEM images of PSMA hydrogels were observed to see the effect of the molecular weight of the cross-linker on the mesh size of the porous microstructure of hydrogels. The hydrogels were swollen completely in deionized water for $48 \mathrm{~h}$ and freeze-dried. Figure 7 showed that all samples had a porous structure. The PSMA hydrogel 1 had the smallest circular porous structure, while the higher molecular weight hydrogels possessed larger pores. As a result, the porosity of the PSMA hydrogel could be manipulated by changing the molecular weight of NPN. Additionally, Table 3 indicated that the swelling ratio increased with the increase in molecular weight of NPN, i. e, the swelling ratios of PSMA hydrogel 1, 4.6 and 10 were measured to be $4.92,8.61$, and $14.58 \%$, respectively. This trend was also observed by others [38,39], which could be explained by the fact that the higher molecular weight of NPN gave more space between PSMA $_{5 \mathrm{k}}$-Tz chains (lower crosslinking density [40, 41]. Consequently, a higher mesh size (evidenced by an increase in the pore size) and equilibrium swelling ratio could be obtained by increasing the molecular weight of NPN.

The mechanical properties of the hydrogels formed in PBS pH 7.4 were evaluated by a rheometer, ARES$\mathrm{G} 2$. The $G^{\prime}$ values of hydrogels were in the range $0.3-1.7 \mathrm{kPa}$ (Table 3). In all frequency range tested $(0.1-100 \mathrm{rad} / \mathrm{s})$, the hydrogels were stable. In the same polymer concentration $(20 \% \mathrm{w} / \mathrm{v})$ and stoichiometric ratio of $\mathrm{Tz}$ to $\mathrm{Nb}$ groups, we found that the $G^{\prime}$ value increased with decreasing the molecular weight of the NPN cross-linker (Figure 8). It indicated that the cross-linker with lower molecular weight had higher mechanical stiffness. This tendency could be attributed to the fact that the higher cross-linking density resulted from the lower molecular weight [42-44]. Moreover, the values of $G^{\prime}$ for the hydrogels

Figure 7. SEM micrographs of the freeze-dried swollen blank PSMA hydrogel; (a) PSMA hydrogel 1, (b) PSMA hydrogel 4.6, (c) PSMA hydrogel 10. 


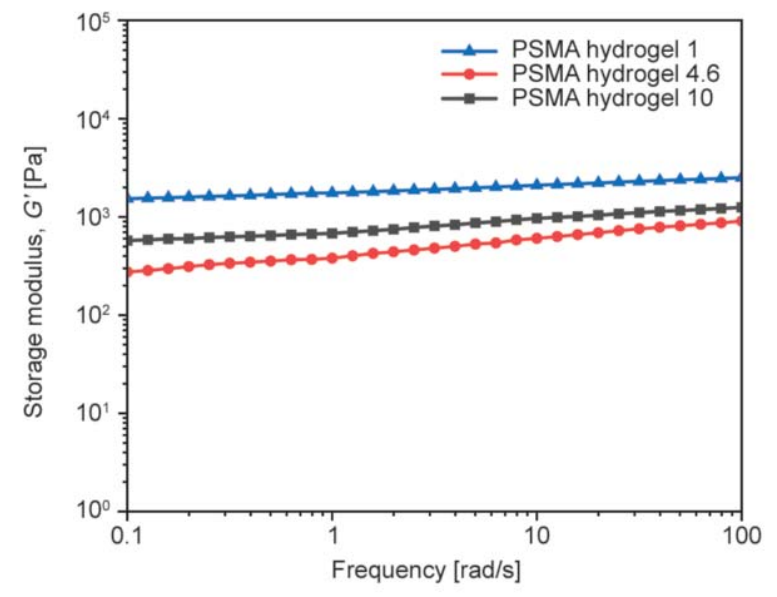

Figure 8. Frequency sweep of PSMA hydrogels.

met the requirement of soft tissue stiffness in the human body (0.1-100 kPa) [45-47].

\subsection{In vitro $\mathrm{DOX} \cdot \mathrm{HCl}$ release from hydrogels}

$\mathrm{DOX} \cdot \mathrm{HCl}$ was used as a model drug to evaluate the PSMA hydrogel as a possible drug carrier. As depicted

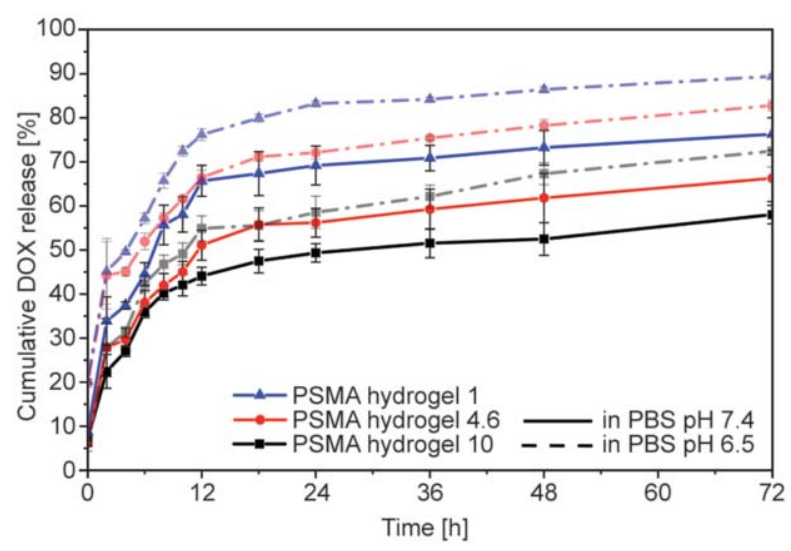

Figure 9. The drug release profile of PSMA hydrogels on PBS pH 7.4 and 6.5.

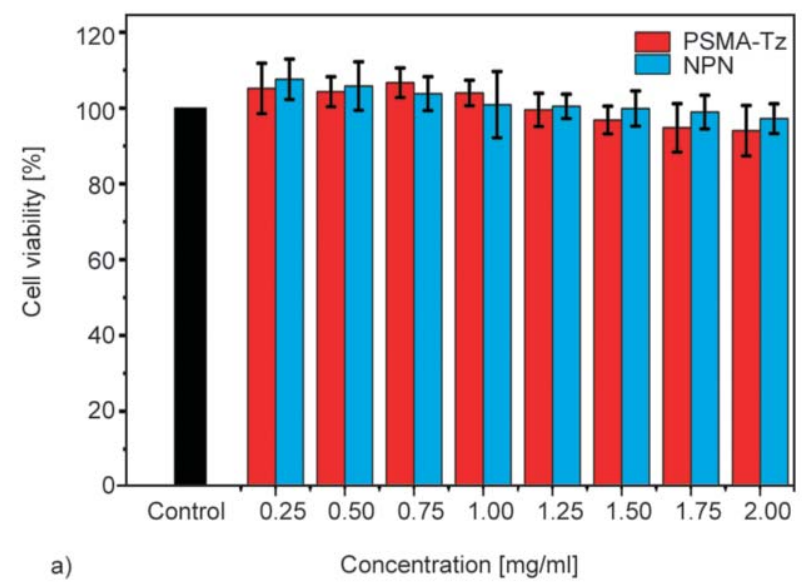

in Figure 9, $\mathrm{DOX} \cdot \mathrm{HCl}$ was released approximately $52-86 \%$ in $48 \mathrm{~h}$ from the hydrogels, and the crosslinker of higher molecular weight tended to increase the release rate of $\mathrm{DOX} \cdot \mathrm{HCl}$. The cumulative release of DOX $\cdot \mathrm{HCl}$ from the PSMA hydrogel 1, 4.6, and 10 was $52.50,61.81$, and $73.24 \%$ at PBS pH 7.4, respectively. On the other hand, the release of $\mathrm{DOX} \cdot \mathrm{HCl}$ at $\mathrm{pH} 6.5$ was higher than at $\mathrm{pH} 7.4$, which were $67.31 \%, 78.26 \%$, and $86.43 \%$ for the PSMA hydrogel $1,4.6$, and 10 . It is likely that the solubility of $\mathrm{DOX} \cdot \mathrm{HCl}$ in water increased with the protonation of amine groups of $\mathrm{DOX} \cdot \mathrm{HCl}$ in an acidic environment [48-51]. The DOX $\cdot \mathrm{HCl}$ release could be administrated by the hydrogel swelling process and diffusion-controlled mechanism [52]. $\mathrm{DOX} \cdot \mathrm{HCl}$ was entrapped in the hydrogel and difficult to diffuse out due to its interaction with PSMA as polymer networks $[22,53]$. As the molecular weight of NPN increased, the DOX $\cdot \mathrm{HCl}$ release became faster. This phenomenon could be explained by the fact that the hydrophilicity of NPN and the higher mesh size of hydrogels facilitated $\mathrm{DOX} \cdot \mathrm{HCl}$ diffusion between the hydrogel matrix and the external aqueous phase [54-56].

\subsection{In vitro cell cytotoxicity of precursors, hydrogels, and DOX $\cdot \mathrm{HCl}$-loaded hydrogels}

The effect of the precursors, hydrogels, and DOX $\cdot \mathrm{HCl}$-loaded hydrogels on HEK 293 and HeLa cells was investigated by using MTT assay to evaluate the cytotoxicity. The MTT assay is a common colorimetric method for cell viability measurement. The cytotoxic effect of the precursors was evaluated on the non-cancerous HEK293 cell line. Figure 10a

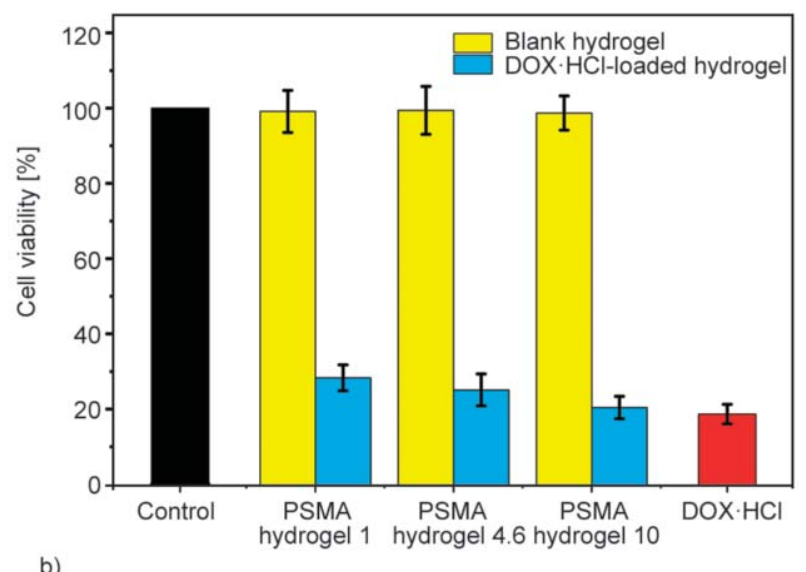

b)

Figure 10. (a) In vitro cell cytotoxicity of HEK293 cell viability evaluated at different concentration of precursors, (b) blank hydrogels, DOX $\cdot \mathrm{HCl}-$ loaded hydrogel and $\mathrm{DOX} \cdot \mathrm{HCl}$ solution on $\mathrm{HeLa}$ cells evaluated by the MTT method. 


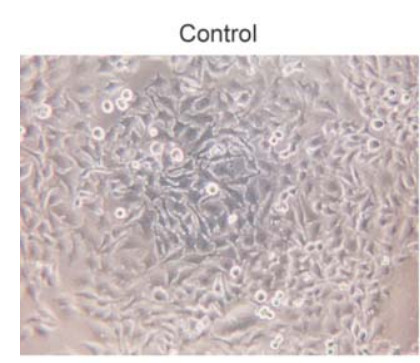

Free DOX. $\mathrm{HCl}$

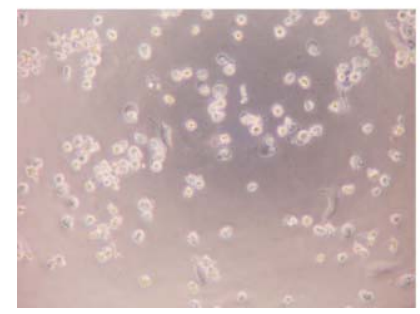

PSMA hydrogel 4.6

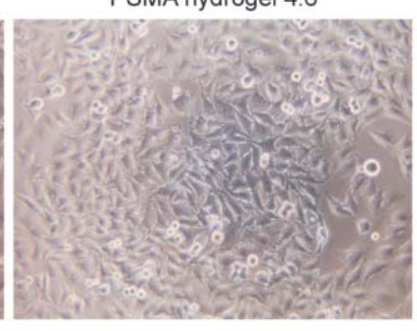

PSMA hydrogel $4.6+\mathrm{DOX} \cdot \mathrm{HCl}$
PSMA hydrogel 10

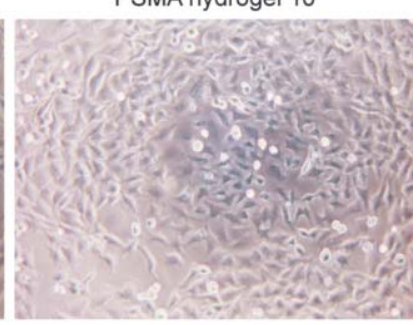

PSMA hydrogel $10+\mathrm{DOX} \cdot \mathrm{HCl}$
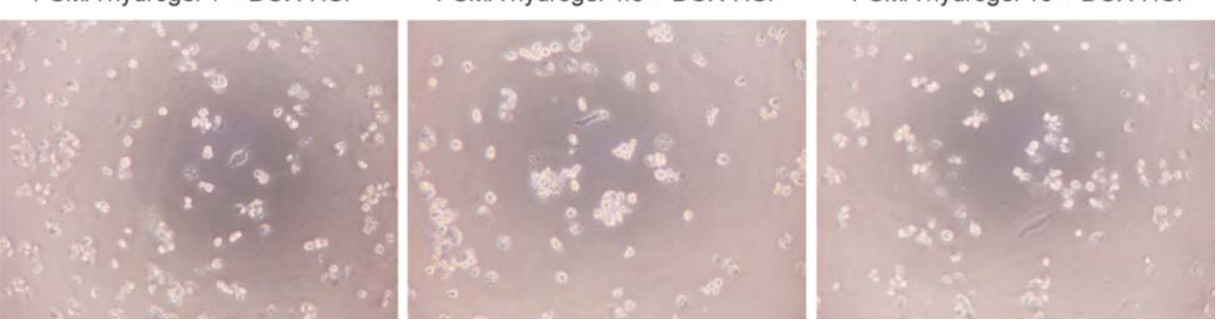

Figure 11. Phase-contrast microscopy images of the HeLa cells incubated with the free DOX $\cdot \mathrm{HCl}$, extracts of blank hydrogels, DOX $\cdot \mathrm{HCl}-$ loaded hydrogels treated for $24 \mathrm{~h}$.

depicts the cell viability and corresponding toxicity level of the precursors at various concentrations. As it can be observed, the precursors did not exhibit any depressing effect on the HEK293 cell growth, indicating the great biocompatibility of the precursors. The extracts of the blank hydrogels in PBS $(0.01 \mathrm{M}$, $\mathrm{pH}$ 7.4) also showed no significant cell growth inhibition on HeLa cells as shown in Figure 10b, which meant that the hydrogels were biocompatible. In contrast, the extracts of the DOX $\cdot \mathrm{HCl}-$ loaded hydrogels revealed strong inhibition of cell viability. It also revealed that $\mathrm{DOX} \cdot \mathrm{HCl}$-loaded extracts had a slightly lower cytotoxic effect than free $\mathrm{DOX} \cdot \mathrm{HCl}$ with the same dose $(15 \mu \mathrm{g} / \mathrm{ml})$, probably due to the sustained release of DOX $\cdot \mathrm{HCl}$ from the hydrogels. Figure 11 displays the morphology of HeLa cells after $24 \mathrm{~h}$ incubation for non-treated cells (control) and treated cells with free DOX $\cdot \mathrm{HCl}$, blank hydrogels, and DOX·HCl-loaded hydrogels. As shown in the images, the morphology and density of the cells treated with the blank hydrogel were similar to control cells after incubation, while detached or less attached cells were observed for the cells treated with free $\mathrm{DOX} \cdot \mathrm{HCl}$ and DOX$\cdot \mathrm{HCl}-$ loaded hydrogels. The comparatively increased cytotoxic effect of the

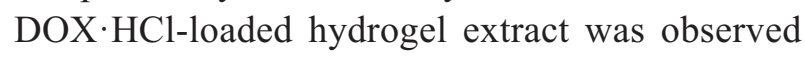
with increasing the molecular weight of the crosslinker in the hydrogels. This result exhibited a correlation with the mesh size and drug release profile of the PSMA hydrogels. The in vitro cell cytotoxicity results indicated that the PSMA hydrogel had good biocompatibility, while the DOX $\cdot \mathrm{HCl}-$ loaded hydrogel could sustain the release of $\mathrm{DOX} \cdot \mathrm{HCl}$ and kill
HeLa cells efficiently, demonstrating that this kind of drug-loaded hydrogels could be a candidate for localized anticancer drug release.

\section{Conclusions}

In summary, injectable, in situ forming PSMA hydrogels were successfully prepared by the click-crosslinking reaction between PSMA ${ }_{5 \mathrm{k}}$-Tz and NPN crosslinkers. PSMA5k was readily synthesized by RAFT polymerization and subsequently functionalized with Tz groups. The hydrogels formed ultrafast within several minutes via IEDDA Tz-Nb 'click' chemistry without any catalyst. The rheology test demonstrated that the hydrogels could reach the requirement of stiffness for bio-applications. The pore size of PSMA hydrogels was suitable for loading and release of $\mathrm{DOX} \cdot \mathrm{HCl}$, which could be manipulated by changing the molecular weight of NPN cross-linkers. The DOX·HCl-loaded PSMA hydrogels showed the higher release of $\mathrm{DOX} \cdot \mathrm{HCl}$ at $\mathrm{pH} 6.5$ compared to $\mathrm{pH}$ 7.4. In vitro cell cytotoxicity test indicated that the precursors and PSMA hydrogels had great biocompatibility. On the other hand, DOX $\cdot \mathrm{HCl}$-loaded hydrogels exhibited a significant toxic effect on the cancer cell. This research could provide a novel strategy to produce safe injectable hydrogels in large-scale applications as a drug depot.

\section{Acknowledgements}

This work was supported by the National Research Foundation of Korea (NRF) Grant funded by the Ministry of Education (NRF-2018R1D1A3B07041437). 


\section{References}

[1] Xavier J. R., Thakur T., Desai P., Jaiswal M. K., Sears N., Cosgriff-Hernandez E., Kaunas R., Gaharwar A. K.: Bioactive nanoengineered hydrogels for bone tissue engineering: A growth-factor-free approach. ACS nano, 9, 3109-3118 (2015).

https://doi.org/10.1021/nn507488s

[2] Xing J-F., Zheng M-L., Duan X-M.: Two-photon polymerization microfabrication of hydrogels: An advanced $3 \mathrm{D}$ printing technology for tissue engineering and drug delivery. Chemical Society Reviews, 44, 5031-5039 (2015).

https://doi.org/10.1039/c5cs00278h

[3] Hoyle C. E., Lowe A. B., Bowman C. N.: Thiol-click chemistry: A multifaceted toolbox for small molecule and polymer synthesis. Chemical Society Reviews, 39, 1355-1387 (2010).

https://doi.org/10.1039/b901979k

[4] Bzymek K. P., Puckett J. W., Zer C., Xie J., Ma Y., King J. D., Goodstein L. H., Avery K. N., Colcher D., Singh G., Horne D. A., Williams J. C.: Mechanically interlocked functionalization of monoclonal antibodies. Nature Communications, 9, 1580/1-1580/9 (2018).

https://doi.org/10.1038/s41467-018-03976-5

[5] Li S., Wang L., Yu X., Wang C., Wang Z.: Synthesis and characterization of a novel double cross-linked hydrogel based on Diels-Alder click reaction and coordination bonding. Materials Science and Engineering C, 82, 299-309 (2018).

https://doi.org/10.1016/j.msec.2017.08.031

[6] Wei Z., Yang J. H., Du X. J., Xu F., Zrínyi M., Osada Y., Li F., Chen Y. M.: Dextran-based self-healing hydrogels formed by reversible Diels-Alder reaction under physiological conditions. Macromolecular Rapid Communications, 34, 1464-1470 (2013).

https://doi.org/10.1002/marc.201300494

[7] Gregoritza M., Brandl F. P.: The Diels-Alder reaction: A powerful tool for the design of drug delivery systems and biomaterials. European Journal of Pharmaceutics and Biopharmaceutics, 97, 438-453 (2015).

https://doi.org/10.1016/j.ejpb.2015.06.007

[8] Crescenzi V., Cornelio L., Di Meo C., Nardecchia S., Lamanna R.: Novel hydrogels via click chemistry: Synthesis and potential biomedical applications. Biomacromolecules, 8, 1844-1850 (2007).

https://doi.org/10.1021/bm0700800

[9] Liu Y., Conboy M. J., Mehdipour M., Liu Y., Tran T. P., Blotnick A., Rajan P., Santos T. C., Conboy I. M.: Application of bio-orthogonal proteome labeling to cell transplantation and heterochronic parabiosis. Nature Communications, 8, 643/1-643/11 (2017).

https://doi.org/10.1038/s41467-017-00698-y

[10] Koehler K. C., Anseth K. S., Bowman C. N.: DielsAlder mediated controlled release from a poly(ethylene glycol) based hydrogel. Biomacromolecules, 14, 538 547 (2013).

https://doi.org/10.1021/bm301789d
[11] Montiel-Herrera M., Gandini A., Goycoolea F. M., Jacobsen N. E., Lizardi-Mendoza J., Recillas-Mota M., Argüelles-Monal W. M.: $N$-(furfural) chitosan hydrogels based on Diels-Alder cycloadditions and application as microspheres for controlled drug release. Carbohydrate Polymers, 128, 220-227 (2015).

https://doi.org/10.1016/j.carbpol.2015.03.052

[12] Li S., Yi J., Yu X., Shi H., Zhu J., Wang L.: Preparation and characterization of acid resistant double crosslinked hydrogel for potential biomedical applications. ACS Biomaterials Science and Engineering, 4, 872883 (2018).

https://doi.org/10.1021/acsbiomaterials.7b00818

[13] Tyler D. S., Vappiani J., Cañeque T., Lam E. Y. N., Ward A., Gilan O., Chan Y-C., Hienzsch A., Rutkowska A., Werner T., Wagner A. J., Lugo D., Gregory R., Molina C. R., Garton N., Wellaway C. R., Jackson S., MacPherson L., Figueiredo M., Stolzenburg S., Bell C. C., House C., Dawson S-J., Hawkins E. D., Drewes G., Prinjha R. K., Rodriguez R., Grandi P., Dawson M. A.: Click chemistry enables preclinical evaluation of targeted epigenetic therapies. Science, 356, 1397-1401 (2017).

https://doi.org/10.1126/science.aal2066

[14] Alge D. L., Azagarsamy M. A., Donohue D. F., Anseth K. S.: Synthetically tractable click hydrogels for threedimensional cell culture formed using tetrazine-norbornene chemistry. Biomacromolecules, 14, 949-953 (2013).

https://doi.org/10.1021/bm4000508

[15] Lang K., Davis L., Torres-Kolbus J., Chou C., Deiters A., Chin J. W.: Genetically encoded norbornene directs site-specific cellular protein labelling via a rapid bioorthogonal reaction. Nature Chemistry, 4, 298-304 (2012).

https://doi.org/10.1038/nchem.1250

[16] Anugrah D. S. B., Ramesh K., Kim M., Hyun K., Lim K. T.: Near-infrared light-responsive alginate hydrogels based on diselenide-containing cross-linkage for on demand degradation and drug release. Carbohydrate Polymers, 223, 115070/1-115070/10 (2019).

https://doi.org/10.1016/j.carbpol.2019.115070

[17] Kim K., Kim M. S.: An injectable hydrogel derived from small intestine submucosa as a stem cell carrier. Journal of Biomedical Materials Research: Part B Applied Biomaterials, 104, 1544-1550 (2016).

https://doi.org/10.1002/jbm.b.33504

[18] Liu M., Zeng X., Ma C., Yi H., Ali Z., Mou X., Li S., Deng Y., He N.: Injectable hydrogels for cartilage and bone tissue engineering. Bone Research, 5, 17014/117014/20 (2017).

https://doi.org/10.1038/boneres.2017.14

[19] Khan M., Koivisto J. T., Hukka T. I., Hokka M., Kellomäki M.: Composite hydrogels using bioinspired approach with in situ fast gelation and self-healing ability as future injectable biomaterial. ACS Applied Materials and Interfaces, 10, 11950-11960 (2018). https://doi.org/10.1021/acsami.8b01351 
[20] Lü S., Gao C., Xu X., Bai X., Duan H., Gao N., Feng C., Xiong Y., Liu M.: Injectable and self-healing carbohydrate-based hydrogel for cell encapsulation. ACS Applied Materials and Interfaces, 7, 13029-13037 (2015). https://doi.org/10.1021/acsami.5b03143

[21] Tacar O., Sriamornsak P., Dass C. R.: Doxorubicin: An update on anticancer molecular action, toxicity and novel drug delivery systems. Journal of Pharmacy and Pharmacology, 65, 157-170 (2013). https://doi.org/10.1111/j.2042-7158.2012.01567.x

[22] Dadsetan M., Liu Z., Pumberger M., Giraldo C. V., Ruesink T., Lu L., Yaszemski M. J.: A stimuli-responsive hydrogel for doxorubicin delivery. Biomaterials, 31, 8051-8062 (2010). https://doi.org/10.1016/j.biomaterials.2010.06.054

[23] Sheng J., Wang Y., Xiong L., Luo Q., Li X., Shen Z., Zhu W.: Injectable doxorubicin-loaded hydrogels based on dendron-like $\beta$-cyclodextrin-poly(ethylene glycol) conjugates. Polymer Chemistry, 8, 1680-1688 (2017). https://doi.org/10.1039/c6py02243j

[24] Gao L., Sun Q., Wang Y., Zhu W., Li X., Luo Q., Li X., Shen Z.: Injectable poly(ethylene glycol) hydrogels for sustained doxorubicin release. Polymers for Advanced Technologies, 28, 35-40 (2017).

https://doi.org/10.1002/pat.3852

[25] Oneto J. M. M., Khan I., Seebald L., Royzen M.: In vivo bioorthogonal chemistry enables local hydrogel and systemic pro-drug to treat soft tissue sarcoma. ACS Central Science, 2, 476-482 (2016).

https://doi.org/10.1021/acscentsci.6b00150

[26] Jivan F., Yegappan R., Pearce H., Carrow J. K., McShane M., Gaharwar A. K., Alge D. L.: Sequential thiolene and tetrazine click reactions for the polymerization and functionalization of hydrogel microparticles. Biomacromolecules, 17, 3516-3523 (2016).

https://doi.org/10.1021/acs.biomac.6b00990

[27] Kawamoto K., Grindy S. C., Liu J., Holten-Andersen N., Johnson J. A.: Dual role for 1,2,4,5-tetrazines in polymer networks: Combining Diels-Alder reactions and metal coordination to generate functional supramolecular gels. ACS Macro Letters, 4, 458-461 (2015). https://doi.org/10.1021/acsmacrolett.5b00221

[28] Subramanian B., Rameshbabu A. P., Ghosh K., Jha P. K., Jha R., Murugesan S., Chattopadhyay S., Dhara S., Mondal K. C., Basak P., Guha S. K.: Impact of styrene maleic anhydride (SMA) based hydrogel on rat fallopian tube as contraceptive implant with selective antimicrobial property. Materials Science and Engineering C, 94, 94-107 (2019). https://doi.org/10.1016/j.msec.2018.09.023

[29] Henry S. M., El-Sayed M. E. H., Pirie C. M., Hoffman A. S., Stayton P. S.: pH-responsive poly(styrene-altmaleic anhydride) alkylamide copolymers for intracellular drug delivery. Biomacromolecules, 7, 2407-2414 (2006). https://doi.org/10.1021/bm060143z
[30] Le C. M. Q., Cao X. T., Tu T. T. K., Gal Y-S., Lim K. T.: Facile approach to prepare $\mathrm{pH}$ and redox-responsive nanogels via Diels-Alder click reaction. Express Polymer Letters, 12, 688-698 (2018).

https://doi.org/10.3144/expresspolymlett.2018.59

[31] Le C. M. Q., Cao X. T., Kim D. W., Ban U. H., Lee S. H., Lim K. T.: Preparation of poly(styrene-alt-maleic anhydride) grafted multi-walled carbon nanotubes for $\mathrm{pH}-$ responsive release of doxorubicin. Molecular Crystals and Liquid Crystals, 654, 181-189 (2017). https://doi.org/10.1080/15421406.2017.1358041

[32] Le C. M. Q., Cao X. T., Lim K. T.: Ultrasound-promoted direct functionalization of multi-walled carbon nanotubes in water via Diels-Alder 'click chemistry'. U1trasonics Sonochemistry, 39, 321-329 (2017). https://doi.org/10.1016/j.ultsonch.2017.04.042

[33] Moghadam P. N., Azaryan E., Zeynizade B.: Investigation of poly(styrene-alt-maleic anhydride) copolymer for controlled drug delivery of ceftriaxone antibiotic. Journal of Macromolecular Science Part A: Pure and Applied Chemistry, 47, 839-848 (2010). https://doi.org/10.1080/10601325.2010.492265

[34] Lai J. T., Filla D., Shea R.: Functional polymers from novel carboxyl-terminated trithiocarbonates as highly efficient RAFT agents. Macromolecules, 43, 122-123 (2002). https://doi.org/10.1021/ma020362m

[35] Devaraj N. K., Weissleder R.: Biomedical applications of tetrazine cycloadditions. Accounts of Chemical Research, 44, 816-827 (2011).

https://doi.org/10.1021/ar200037t

[36] Kumar A., Hao G., Liu L., Ramezani S., Hsieh J-T., Öz O. K., Sun X.: Click-chemistry strategy for labeling antibodies with copper-64 via a cross-bridged tetraazamacrocyclic chelator scaffold. Bioconjugate Chemistry, 26, 782-789 (2015).

https://doi.org/10.1021/acs.bioconjchem.5b00102

[37] Hansell C. F., Espeel P., Stamenović M. M., Barker I. A., Dove A. P., Du Prez F. E., Oreilly R. K.: Additivefree clicking for polymer functionalization and coupling by tetrazine-norbornene chemistry. Journal of the American Chemical Society, 133, 13828-13831 (2011). https://doi.org/10.1021/ja203957h

[38] Xu Z., Li J., Zhou H., Jiang X., Yang C., Wang F., Pan Y., Li N., Li X., Shi L., Shi X.: Morphological and swelling behavior of cellulose nanofiber (CNF)/poly (vinyl alcohol) (PVA) hydrogels: Poly(ethylene glycol) (PEG) as porogen. RSC Advances, 6, 43626-43633 (2016). https://doi.org/10.1039/c6ra03620a

[39] Autissier A., Le Visage C., Pouzet C., Chaubet F., Letourneur D.: Fabrication of porous polysaccharide-based scaffolds using a combined freeze-drying/cross-linking process. Acta Biomaterialia, 6, 3640-3648 (2010). https://doi.org/10.1016/j.actbio.2010.03.004 
[40] Buenger D., Topuz F., Groll J.: Hydrogels in sensing applications. Progress in Polymer Science, 37, 16781719 (2012).

https://doi.org/10.1016/j.progpolymsci.2012.09.001

[41] Bae K. H., Wang L-S., Kurisawa M.: Injectable biodegradable hydrogels: Progress and challenges. Journal of Materials Chemistry B, 1, 5371-5388 (2013).

https://doi.org/10.1039/c3tb20940g

[42] Atzet S., Curtin S., Trinh P., Bryant S., Ratner B.: Degradable poly(2-hydroxyethyl methacrylate)-co-polycaprolactone hydrogels for tissue engineering scaffolds. Biomacromolecules, 9, 3370-3377 (2008).

https://doi.org/10.1021/bm800686h

[43] Trappmann B., Chen C. S.: How cells sense extracellular matrix stiffness: A material's perspective. Current Opinion in Biotechnology, 24, 948-953 (2013). https://doi.org/10.1016/j.copbio.2013.03.020

[44] Zustiak S. P., Leach J. B.: Hydrolytically degradable poly(ethylene glycol) hydrogel scaffolds with tunable degradation and mechanical properties. Biomacromolecules, 11, 1348-1357 (2010).

https://doi.org/10.1021/bm100137q

[45] Discher D. E., Janmey P., Wang Y-L.: Tissue cells feel and respond to the stiffness of their substrate. Science, 310, 1139-1143 (2005).

https://doi.org/10.1126/science.1116995

[46] Engler A. J., Sen S., Sweeney H. L., Discher D. E.: Matrix elasticity directs stem cell lineage specification. Cell, 126, 677-689 (2006).

https://doi.org/10.1016/j.cell.2006.06.044

[47] Bakaic E., Smeets N. M. B., Hoare T.: Injectable hydrogels based on poly(ethylene glycol) and derivatives as functional biomaterials. RSC Advances, 5, 3546935486 (2015).

https://doi.org/10.1039/c4ra13581d

[48] Meng F., Zhong Y., Cheng R., Deng C., Zhong Z.: pHsensitive polymeric nanoparticles for tumor-targeting doxorubicin delivery: Concept and recent advances. Nanomedicine, 9, 487-499 (2014).

https://doi.org/10.2217/nnm.13.212

[49] Mashima T., Sato S., Sugimoto Y., Tsuruo T., Seimiya H.: Promotion of glioma cell survival by acyl-CoA synthetase 5 under extracellular acidosis conditions. Oncogene, 28, 9-19 (2009).

https://doi.org/10.1038/onc.2008.355
[50] Goetz J. G., Minguet S., Navarro-Lérida I., Lazcano J. J., Samaniego R., Calvo E., Tello M., Osteso-Ibáñez T., Pellinen T., Echarri A., Cerezo A., Klein-Szanto A. J. P., Garcia R., Keely P. J., Sánchez-Mateos P., Cukierman E., Del Pozo M. A.: Biomechanical remodeling of the microenvironment by stromal caveolin-1 favors tumor invasion and metastasis. Cell, 146, 148-163 (2011). https://doi.org/10.1016/j.cell.2011.05.040

[51] Zhao X., Liu P.: Reduction-responsive core-shell-corona micelles based on triblock copolymers: Novel synthetic strategy, characterization, and application as a tumor microenvironment-responsive drug delivery system. Applied Materials and Interfaces, 7, 166-174 (2014). https://doi.org/10.1021/am505531e

[52] Wu Y., Wang H., Gao F., Xu Z., Dai F., Liu W.: An injectable supramolecular polymer nanocomposite hydrogel for prevention of breast cancer recurrence with theranostic and mammoplastic functions. Advanced Functional Materials, 28, 1801000/1-1801000/12 (2018). https://doi.org/10.1002/adfm.201801000

[53] Lee S. J., Bae Y., Kataoka K., Kim D., Lee D. S., Kim S. C.: In vitro release and in vivo anti-tumor efficacy of doxorubicin from biodegradable temperature-sensitive star-shaped PLGA-PEG block copolymer hydrogel. Polymer Journal, 40, 171-176 (2008). https://doi.org/10.1295/polymj.PJ2007179

[54] Weber L. M., Lopez C. G., Anseth K. S.: Effects of PEG hydrogel crosslinking density on protein diffusion and encapsulated islet survival and function. Journal of Biomedical Materials Research Part A, 90, 720-729 (2009). https://doi.org/10.1002/jbm.a.32134

[55] Pakulska M. M., Donaghue I. E., Obermeyer J. M., Tuladhar A., McLaughlin C. K., Shendruk T. N., Shoichet M. S.: Encapsulation-free controlled release: Electrostatic adsorption eliminates the need for protein encapsulation in PLGA nanoparticles. Science Advances, 2, e1600519/1-e1600519/10 (2016). https://doi.org/10.1126/sciadv.1600519

[56] Lee S., Tong X., Yang F.: Effects of the poly(ethylene glycol) hydrogel crosslinking mechanism on protein release. Biomaterials Science, 4, 405-411 (2016). https://doi.org/10.1039/c5bm00256g 